\title{
Collaborative and Cooperative E-learning in Higher Education in Morocco: A Case Study
}

\author{
http://dx.doi.org/10.3991/ijet.v9i1.3065 \\ Abdelaziz Bouroumi and Rkia Fajr \\ Hassan II Mohammedia-Casablanca University, Casablanca, Morocco
}

\begin{abstract}
In this paper, we present the results of a case study concerning the introduction of new online technologies in order to support collaborative and cooperative learning strategies in higher education in Morocco. This study was conducted using the online version of a one semester course designed for two groups of master students at Ben M'sik Faculty of Sciences, Hassan II Mohammedia-Casablanca University. It was based on the Moodle platform's e-learning tools that support these learning strategies, which were totally new for most of students enrolled in this course. The study results show significant improvements in students' overall performance, compared to previous sessions of the course that were delivered in traditional non-online forms.
\end{abstract}

Index Terms-E-learning, Moodle, collaborative learning, cooperative learning, constructivism, constructionism.

\section{INTRODUCTION}

Finding out the best learning strategies and the best way to apply them in order to allow students optimize their benefits from learning experiences has always been a challenge for both students and educators. During the last few decades, new learning strategies have been introduced in education and training systems in order to enhance students' performance, particularly in the field of higher education [1-3]. More recently, the combination of these strategies with new technologies, and their implementation and support by specialized e-learning platforms, have lead to the apparition of new forms of learning that are dramatically changing the traditional roles of both teachers and learners, where learning is no longer about content transfer but rather about knowledge construction and skills development.

Unlike traditional learning approaches, which focus on interactions between teachers and students, and between students and course contents and materials, modern strategies make use of different other kinds of interactions between students and their classmates, as well as between groups of students.

Collaborative learning and cooperative learning are typical examples of non-traditional learning strategies that are based on interactions between students, which are easily supported by new technologies, and that can be more effective than traditional approaches for which interactions and collaboration between students are generally not allowed [1].

Internet and new technologies have facilitated the implementation of these strategies by specialized e-learning platforms, leading to the emergence of new forms of education and training, particularly on-line and distance learning that facilitate and encourage different forms of collaboration and cooperation between learners.

Moreover, the apparition of specialized e-learning platforms in the form of open source and freely available software has recently made it possible for virtually any educator to design online courses intended to Internetbased communities of learners that can work and learn collaboratively.

The main goal of this paper is to present and discuss the experimental results of a practical case study concerning the introduction of new e-learning technologies to support collaborative and cooperative learning strategies in higher education in Morocco; which is technically feasible at least for engineering and master science students whose individual and permanent access to the Internet is guaranteed and financially supported by a Government's national program [8].

The study concerned a typical example of master courses initially designed for a master in information processing in 2006. This course, whose pedagogical approach is based on collaborative and cooperative strategies, was then adopted in 2009 by another master in modeling and simulation. From 2006 to 2009 the course was given in traditional forms, and in 2010 an online version was developed and used for both masters.

In the next section, after briefly recalling the basic concepts and principles of cooperative and collaborative learning strategies, we present the main e-learning tools we used for implementing online activities that require collaboration and cooperation between students. Experimental results are numerically presented and discussed in section III. Final, our conclusion, remarks and suggestions are given in section IV.

\section{COLLABORATION, COOPERATION, AND E- LEARNING}

\section{A. Collaborative learning and cooperative learning}

Collaborative learning and cooperative learning are teaching strategies that allow students to interact with each other and work together in order to learn more efficiently. Based on the principle that learning is inherently a social process, these strategies give learners the opportunity to interact with each other, discuss ideas, think and talk together, analyze and solve problems in groups, create and realize common projects, etc.

Cooperative learning is a special type of collaborative learning in which small groups of students work together on well-structured activities, guided by clear objectives, and where the work of each student as well as the whole work of each group is assessed by a supervisor or tutor. 
The main difference between these two strategies is that collaborative learning focuses on comparing outcomes of both collaborative and individual works, whilst cooperative learning focuses only on the effectiveness of cooperation and not on individual works [6]. Despite this difference, both strategies share, however, a common goal: promoting the engagement of students in their learning process.

Research in these fields has proven that for a collaborative or cooperative learning to be effective, five conditions should be satisfied [3]. The first condition is positive interdependence, which means that students should necessarily feel that their individual success depends not only on their individual work, but also on the work of all other members of their groups. Thus, each student should perform his or her own tasks, ensuring that all members of his or her group can also perform theirs. Therefore, the success cannot be individual but common to and shared by all group members.

The second condition is individual accountability. It means that although each individual is assessed for the part of the work she or he is responsible for, the assessment result is not given to the individual but to the whole group.

The third condition is promotive interaction, which means that all members of each group could help each other to get more effective results. This condition can be ensured by encouraging students to discuss and exchange ideas, opinions, and comments about the work, as well as by allowing and encouraging them to provide assistance for all those who need it.

The fourth condition is social skills. It means that the whole group should benefit from the social skills of all of its members. For this, each student should have the possibility to freely express his or herself, to listen to other learners, and to participate in solving any possible conflicts.

The fifth and last condition is group processing. It means that all students should be given the opportunity to participate in analyzing the whole work of their groups, as well as to freely give their points of view about the work progression and its intermediate results, to propose new strategies for future steps, etc.

In section III we will see that it is only under these five conditions that collaborative and cooperative strategies can be really efficient.

\section{B. E-learning platforms and collaborative work}

E-learning platforms are specific web-based applications, also called learning management systems or virtual learning environments, which educators can use as tools for designing and creating on-line courses, and students as dynamic websites for learning and collaborating with other students, without time and space constraints of traditional face to face learning.

Since the apparition of the World Wide Web in the early 1990s, many e-learning platforms have been developed. Some of these platforms were conceived as a means for minimizing costs, and did not take into account any social aspect of learning; focusing only on how prepackaged contents can be delivered to the maximum number of learners using information technology and computer networks. By contrast, other platforms were initially designed based on the pedagogical principles of social constructiv- ism and constructionism. These platforms offer different tools for implementing these principles via two-way communications between teachers and learners, as well as between learners and other learners [7].

Assuming that knowledge is socially constructed, platforms of this last category emphasize social aspects of learning, and provide tools that facilitate collaboration and communication among groups of learners that work together in order to achieve common goals.

The platform we used in this study is Moodle, which is a free, open source and publicly available content management system [9]. It offers many tools for creating communities of learners around educational contents, based on the pedagogical principles of social constructivism and constructionism.

One of the most commonly used tools for collaborative communication among learners is the discussion forums. Using this tool, instructors can easily create discussion forums and propose them as activities for groups of students to discuss and exchange ideas about specific themes. Thus, each participant to each forum can post new questions related to the theme of the forum, answer questions posted by other participants, with the possibility of including links or attachments into each posted message, propose new topics of discussion, etc. In Moodle, although this type of communication is asynchronous, whenever a new post is added to a forum, all participants to this forum may be automatically alerted via e-mail. For instructors, discussion forums can be very useful for determining the level of involvement of each student and adjusting, if necessary, the adopted learning strategy.

The second tool is real-time text-based on-line chat, which is a familiar form of synchronous communication. In Moodle, real-time chat sessions can easily be created as activities that simulate interactions of students when they talk together, discuss and present their points of view, and participate in the advancement of a group work.

The third tool that instructors can use for designing useful activities for groups of students is the quiz tool. Quiz activities are very useful for students as a means of selftesting and for instructors as a means of formative evaluations. Formative evaluations are assessment procedures that take place during the learning process for adjusting the learning strategy by adapting it to the global level of students. They are consistent with the constructivist approach of learning and give rise to qualitative feedbacks, which generally inform discussion forums and chat sessions.

\section{EXPERIMENTAL RESULTS AND DISCUSSIONS}

In this section, we present and discuss the experimental results of our case study, which was conducted over a full semester on two groups of 24 and 23 students from two different masters but all enrolled in a common course of algorithms and programming. The on-line version of this course was, which we used as a basis for this study, has been hosted by the Moodle platform of the Coselearn Project since 2010 (Fig. 1).

Coselearn is a program of the Swiss agency for development and cooperation, aimed at promoting e-learning in several African francophone countries, including Morocco [10]. 
PAPER

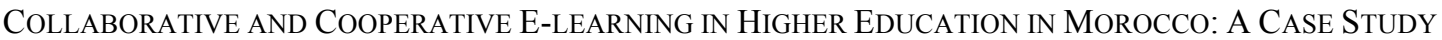

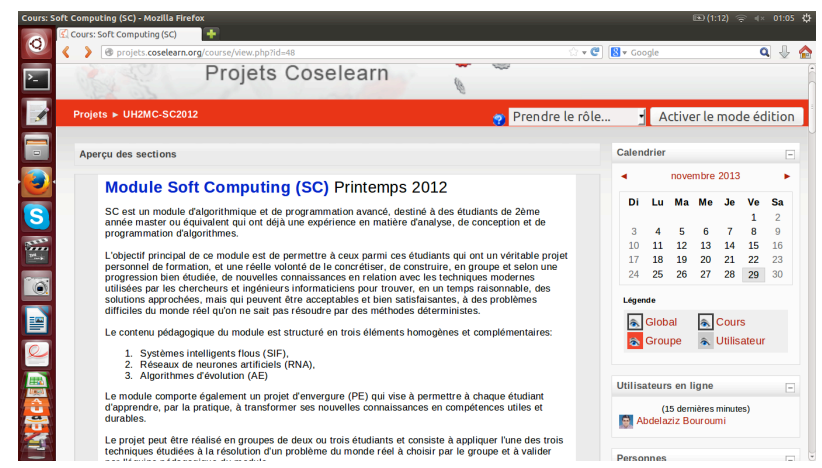

Figure 1. Home page of the used course on the Moodle platform of the Coselearn Project.

The course was permanently accessible via the Internet to all students of both groups involved in this study thanks to the Injaz initiative, which is part of the national program "Maroc numeric 2013", aimed at facilitating access to the Internet for engineering and masters of science students. This initiative consists in financially supporting students in buying personal laptops with mobile access to broadband Internet at only $15 \%$ of the actual cost [8].

It is a full-semester module consisting of three homogenous and complementary parts whose contents were designed to engage students in collaborative and cooperative works since the beginning of the course. These contents include online resources that each student of each group has to study, analyze, and discuss with other students of his or her own group in order to collaboratively build new knowledge, plus online activities designed to help learners of each group transform their newly acquired knowledge into useful and sustainable skills using practical and quite challenging exercises, in competition with learners of the other group.

The course contents, objectives, syllabus -as well as its newly adopted pedagogical strategy- were presented and explained in a first face to face session regrouping all students. The e-learning platform and its main tools were then presented in two separate face-to-face sessions, during which students of each group were separately invited to activate their previously created individual access accounts to the platform, complete their account profiles, and discover the different constituents of the course site.

During these sessions, a special attention was given to the difference between resources and activities, as well as to the necessity for each student to have her or his own learning project, with clearly defined goals, and to make use of the electronic tools provided by the platform for communicating with other students in order to achieve these goals collaboratively.

Furthermore, and in addition to online activities, students were also required to cooperate, under the supervision of a teacher, within smaller teams of two to four members on practical projects that need face to face meetings and discussions in addition to online communications.

Our first finding at this stage of the experiment, particularly after the two face-to-face preliminary sessions, was the very positive and encouraging feedbacks of all students enrolled in the course. We also found that students didn't encounter any significant problems or difficulties in using the chosen platform, and have all manifested great interest in the proposed teaching strategy, which was absolutely new for them, but that offered them new learning ways to explore and experiment.

Moreover, as the course progressed a significant increase of students' engagement was clearly observed, accompanied by clear improvement in accountability for achieving results, by comparison with ancient cohorts of students who previously took the same course, with the same practical and cooperative exercises, but in its traditional non-online form. For ancient students the level of personal engagement, experiment, and communication was indeed quite lower, and has clearly affects their global achievements.

\section{A. Collaboration through the forums tool}

In addition to news forums that have replaced classical announcement boards, and a common global forum which was dedicated to general discussions about the three parts of the course, many other forums were separately created for each group and each part of the course. Each forum was configured such that all members of the corresponding group could be automatically subscribed to it; meaning that whenever a new post is added to any forum all members of the corresponding group are automatically informed via an e-mail message.

Thus, by separating the two groups a factor of intergroup competition was also indirectly introduced and its effect perceived during all the semester.

Numerical results about the registered activities in the different forums are summarized in Table I. For each part of the course, this table shows the number of new discussion topics proposed by students, as well as the number of active participations, i.e., the number of answers posted to the forum, and the total number of its consultations without necessarily posting any answers or comments.

TABLE I.

NuMBER OF DisCUSSIONS, PARTICIPATIONS AND CONSULTATIONS PER FORUM

\begin{tabular}{|c|c|c|c|}
\hline Forum & Discussions & $\begin{array}{c}\text { Participation } \\
\text { s }\end{array}$ & Consultations \\
\hline General & 21 & 10 & 1984 \\
\hline Part 1 & 83 & 65 & 5012 \\
\hline Part 2 & 12 & 26 & 1089 \\
\hline Part 3 & 3 & 3 & 379 \\
\hline
\end{tabular}

A brief analysis of these data shows that 41 among the 47 students, i.e. more than $87 \%$, have participated to the collaborative work through forums at least by reading the posts of their group-mates.

Furthermore, by analyzing the contents of the different questions, answers, comments, and suggestions students posted to these different forums we found that as the course progressed, a significant improvement in writing styles, global communication abilities, and self-esteem was perceived among all students who actively participated in the discussions by either posting new questions or new topics of discussion, or by answering questions posted by other participants.

On the other hand, many students whose participation was limited to reading the posts of others have declared, offline, that the discussion forums were of great help for them in clarifying many relatively difficult points of the course, as well as in enhancing their global achievements 
in both understanding the course resources and performing the practical activities.

These results show that the global interest of students in communicating and sharing information with their peers in order to collaboratively construct new common knowledge, as well as their engagement in this constructing process are by far greater than what was usually observed for students who have taken the same course in previous years, but in its traditional non-online form. For previous students indeed, although the same strategies of collaboration and cooperation were adopted as the pedagogical approach of the course, and students were persuaded, encouraged and expected to work and learn collaboratively, the lack of online communication tools through a specialized e-learning platform has seriously limited both the interest in and the benefits from these strategies.

Another result that is worth noting is the number of active participations per discussion. As depicted on Fig. 2, this number shows that although all discussion subjects and questions have been consulted many times, $26 \%$ of these discussions and questions haven't received any answer, whilst $22 \%$ have received only one answer, and the remaining $52 \%$ from 2 to 10 answers.

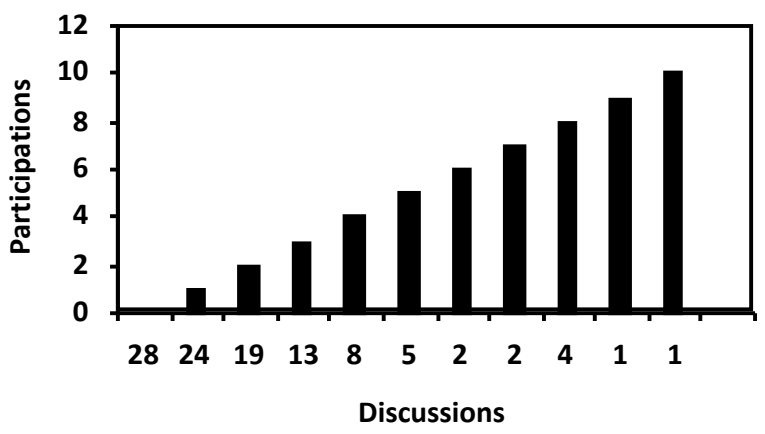

Figure 2. Number of active participations per discussion

This result can be explained by the existence of different classes of behavior within the set of involved students, which correspond to different attitudes regarding the learning community they formed. Indeed, some students, who formed the first observed category of behavior, were only interested in defending or imposing their points of view, without trying to understand different other points of view expressed by other learners. By contrast, other students participated by asking new questions and proposing new subjects of discussion, but also by listening to others and trying to understand their points of view. Finally, a third class was formed by students who knew when to defend their points of view and when to try to understand the others.

We remark that these results are consistent with the three well-known behavior classes across individuals involved in any discussion, namely separate, connected and constructed behaviors [11]. We also found that, in our particular case, the dominant attitude among all participants to the study case was separate behavior, which is a very encouraging result.

\section{B. Collaboration through the real-time text chat tool}

Beside discussion forums that offer an asynchronous online communication tool, the Moodle platform also implements a chat tool that allows teachers to plan period- ical chat sessions and propose them as activities for students to simulate their face to face meetings and interactions without constraints of space. In this study, however, although many weekly chat sessions were programmed, we found that interest in these activities was very low for the majority of students. This finding can be explained by at least three different factors, all specific to the context of the case study. First, students did not really feel the need to simulate face to face discussions because they were not actually separated by distance. Indeed, other traditional non-online courses, plus the practical and cooperative activities associated with this online course, gave them several occasions of daily meeting. Second, the majority of students preferred to limit their chat sessions to small groups of close friends using external chat tools they are already familiarized with, such as the chat service associated with their external e-mail accounts, as well as online social networks based on friendships. Thirdly, since Moodle internal chat sessions may be automatically recorded as part of the course archive, students who didn't want their discussions to be recorded preferred external chat tools, which offered them more freedom of expression with less formal constraints.

Nevertheless, regardless of their preferred chat tools, most students have reported that chat activities helped them in sharing experiences, additional resources, and suggestions related to many aspects of the course, especially some aspects related to some hard questions encountered in the quizzes, which needed to be addressed urgently.

\section{Formative and summative assessments through the quiz tool}

Online quizzes are extraordinary tools for quick, precise, focused and objective tests, assessments and evaluations. Generally speaking, three different types of tests or assessments can be considered for any course. The first type is diagnostic assessment or pre-assessment, which can be very useful for providing teachers with information about students' prior knowledge before even starting the course. Such information can be exploited for developing the course plans and strategies according to students' specific needs and prerequisites. In our case, diagnostic assessments were not necessary because students accepted in the two masters were all selected through a series of tests whose results provided the information needed about their course prerequisites.

The second type is formative assessments, which can be used as a complement to formal exams aimed at improving the learning achievements. Formative assessments take place during the course progression, typically at the end of each part or chapter. Their results can be very helpful for both students and teachers. Teachers, for example, can use formative assessments results as a basis for adjusting the course plans and strategies as needed to optimize the global performance of students. Students, on their part, can use their proper scores and the feedbacks they probably receive with these scores for the purpose of determining, for example, the parts of the course they need to review more, either individually or in collaboration with other students who are in the same situation.

In this study, we used the Moodle's quiz tool for designing three different formative assessments and proposing them as mandatory online activities for all students of the two groups. Each of these quizzes was designed using 
several types of questions, including multiple choice questions with one or more correct answers, short answer questions, numerical answer questions, essay questions, calculated multi-choice questions, matching questions, calculated questions, and description questions.

Furthermore, for each these quizzes we fixed the number of attempts to two and the grading methodology to the best score; meaning that each student was allowed to take the same quiz twice, and to have the best score as final mark. However, although the number of questions remained the same for each attempt and each student, the posed questions could slightly change from one student to another and from one attempt to another for the same student. Indeed, for each part of the course, the quiz questions were randomly chosen from a bank of questions that contains at least four times the number of questions proposed in each quiz attempt.

Moreover, in addition to numerical scores, each student received after each attempt and for each answered question a qualitative feedback on the form of a linguistic expression such as "excellent," "good," "very good," "average," "you need to review this part of the course," "you need to review the following resources," "here is a resource that may help you improve you score," etc.

These personalized feedbacks, plus the possibility to retake the quizzes more than once, plus the possibility and encouragement to review specific parts of the course in collaboration with other students before each new attempt, plus the possibility of online collaboration with no constraints of time and space, have all been new and important factors that tremendously modify the traditional behavior of students, who visibly became more engaged in their learning projects, more active and more aware of their proper responsibilities in constructing their new knowledge, and -most importantly- more confident in themselves and their ability to achieve a common goal with a community of co-learners collaborating online.

The third type of tests is summative assessments. A summative assessment is generally given at the end of a course in order to evaluate students understanding and mastery of the course. In this study, we used, like in previous non-online sessions of the same course, two summative assessments; the first one as a midterm exam, and the second as a final exam. Both of these exams was based on the same types of questions as assessment tests, but the number of attempts was limited, like in traditional nononline exams, to just one attempt. In addition, unlike other online tests that students could take at any place and any time before a fixed deadline, we organized the two summative tests in a monitored classroom, in a fixed time, and under the supervision of teachers. Hence the possibility of comparing results to those obtained in previous years before introducing new online technologies in the pedagogical and evaluation strategies of the course.

Table II summarizes numerical information and results related to the five formative and summative tests we used in this study, plus, on the last column, the best average scores obtained in the five equivalent traditional exams by three previous cohorts of students who had received the same course, using the same principles of collaboration and cooperation, but in its classical and non-online form.

For each online test, the information provided by table II includes the total number of questions, the duration of the test in minutes, the maximum number of allowed
TABLE II.

NUMERICAL RESULTS OF ONLINE FORMATIVE AND SUMMATIVE ASSESSMENTS, COMPARED TO OLD NON-ONLINE SCORES

\begin{tabular}{|c|c|c|c|c|c|}
\hline $\begin{array}{c}\text { Quiz } \\
\text { Subject }\end{array}$ & $\begin{array}{c}\text { Number } \\
\text { of } \\
\text { questions }\end{array}$ & $\begin{array}{c}\text { Durat- } \\
\text { ion } \\
(\boldsymbol{m n})\end{array}$ & $\begin{array}{c}\text { Number } \\
\text { of } \\
\text { attempts }\end{array}$ & $\begin{array}{c}\text { Average } \\
\text { score } \\
(\%)\end{array}$ & $\begin{array}{c}\text { Best old } \\
\text { score } \\
\text { (\%) }\end{array}$ \\
\hline Part 1 & 28 & 15 & 2 & 85.90 & 58.14 \\
\hline Part 2 & 32 & 20 & 2 & 100.00 & 63.10 \\
\hline Part 3 & 30 & 20 & 1 & 69.81 & 52.30 \\
\hline $\begin{array}{c}\text { Midterm } \\
\text { exam }\end{array}$ & 10 & 40 & 1 & 38.46 & 50.76 \\
\hline $\begin{array}{c}\text { Final } \\
\text { exam }\end{array}$ & 30 & 15 & 1 & 95.00 & 74.28 \\
\hline
\end{tabular}

attempts, and the average score -calculated in percentage for all students enrolled in the course-. For old classical exams, the information about scores is given for the purpose of comparisons with equivalent online tests.

The most remarkable result in table II is the $100 \%$ average score for the second formative test, for which two different attempts were allowed. This remarkable score for the whole class can be explained by the intense activity of collaboration and online communication that has been observed during the period preceding the last deadline for taking the second and last attempt of the test. This collaboration took different forms: questions posted on the forums, chat sessions, face to face meetings and discussions, questions directly posed to teachers, etc.

For the first formative test, however, although two different attempts were also allowed, the average score did not exceed $85 \%$. This is because some students, whose score in the first attempt was not very good, did not wait long enough before taking the second attempt, nor did they try to collaborate and communicate with others in order to clarify parts of the course where they didn't perform well. Consequently, the second attempt of these students did not actually improve their scores. For few of them, the recorded score has even diminished after the second attempt because questions, albeit focusing on the same theme, were not necessarily identical to those of the first attempt. By contrast, students who chose to collaboratively review the course before making the second attempt did significantly improve their individual scores.

Compared to the best average score of $58.14 \%$ obtained over three previous years in the traditional exam concerning the same part of the course, this result is, however, much more better despite the many efforts that have been deployed during those years to encourage students work together and learn collaboratively.

To verify whether students were able to maintain the relatively high average scores recorded in the two first formative tests, we decided to limit the number of attempts for the third formative test to just one attempt. Results of this operation showed a non-negligible drop in level, but the average score recorded, 69.81, remains better than the best average score of $52.30 \%$ obtained over the three previous years in the classical exam corresponding to the same part of the course.

For the midterm exam, we decided to create similar conditions to those of traditional written exams. For this, we reduced the number of questions from around 30 to only 10 questions; we doubled the exam duration, which passed from $20 \mathrm{mn}$ to $40 \mathrm{mn}$; and we limited the questions 
types to traditional ones, i.e., questions that require writing out lengthy answers.

The results of this experiment showed a significant drop in the average score over all students to less than $40 \%$, which is even lower than the best average score of $50.76 \%$ obtained over the three previous classical midterm exams. This somewhat surprising result means that, at least in the particular case of this course, performance-based tests could be more effective and more appropriate for evaluating the outcomes of the course than classical written exams, which generally focus on the acquired knowledge, rather than on the practical skills and performances developed on the basis of this knowledge. This also means that classical written exams cannot be appropriately and efficiently implemented as online tests, especially when answers to the test questions should be given on the form of scientific texts with mathematical proofs and formulas.

Finally, for the fifth and last online test, which constitutes the final summative exam, our decision was based on the course objective of transforming the collaboratively acquired knowledge into useful and sustainable skills and performances. For this, focusing mainly on questions of performance-testing type, we fixed the size of the test in terms of number of questions to three times the size of the midterm exam, the test duration to less than half the duration of the midterm exam; and we limited to one the number of allowed attempts. Moreover, although the posed questions were the same for all candidates, the order of these questions and the order of possible answers in the case of multiple choice questions were randomly and automatically modified from one candidate to another.

A desirable effect of this later decision was the disappearance of cheating attempts that are common in traditional written exams. We recall that, like traditional exams, the midterm and the final exams took place in monitored classrooms and under the supervision of teachers; but unlike traditional exams, questions and answers were given online using computers instead of papers, and the scoring of the exam was automatically and instantly ensured by the e-learning platform. Consequently, students were able to receive their scores immediately after the end of the exam, which is unimaginable with traditional nononline exams.

Finally, despite the relative difficulty of this last and final exam, the obtained results show, as depicted on table II, a clear improvement in the global performance of students, as measured by their average score, in comparison with the other tests, which are relatively lees difficult. The average score of $95 \%$ recorded in the final exam was also better than the best average score of $74.28 \%$ obtained in the final exam over the three years preceding the introduction of the online version of the course.

\section{Cooperation through practical projects}

As we previously mentioned, one of the main objectives of the course we used as a basis for this study case is the transformation of collaboratively constructed knowledge into useful and sustainable skills related to the theme of the course. For this, the course program includes a far-reaching practical project, which is a mandatory task for each student. Technically speaking, this project consists in designing and implementing, within small teams of 2 to 4 students, a software solution to a challenging problem, using one of the three modeling techniques whose study constitutes the goal of the three other parts of the course. For each team, the duration of the project is between 4 and 6 weeks. Moreover, the realization of each project is supervised and evaluated by a teacher, each team is free to choose the preferred problem to solve, and each student is free to choose the preferred team to belong to.

In previous years, the cooperation between students working in a team on the same project was quite hard to implement, despite all the advice and recommendations of teachers and supervisors. The main reason of this difficulty was the constraints of time and space. Indeed, a part from the breaks between class-periods and the weekly meetings with supervisors, there was little opportunity for these students, who lived off-campus in a big city, for meeting and working cooperatively.

As to the use of new technologies to support cooperative learning, it was almost limited to communicating via e-mail, despite the fact that all concerned students were equipped with personal laptops with permanent highspeed Internet connections. This limited use of new technologies in cooperative learning was mainly due to the lack of a specialized e-learning platform that could be used for this purpose.

By introducing the online version of the course, using the Coselearn project's Moodle platform [10], this lack has been easily overcame, offering students the opportunity of working cooperatively, online and without constraints of time and space.

Thus, for each of the 19 defined projects a dedicated forum was created and proposed as a mandatory activity for all members of the corresponding team. Each forum was used by all its participants for communicating and discussing, under the supervision of a teacher, all aspects related to their particular project.

In addition to answering difficult and unsolved questions posted by students on the forums, providing directions and recommendations, defining and distributing new tasks, the role of supervisors consisted also in evaluating and numerically assessing the individual participation of each member, as well as the whole work of each team.

Finally, at the end of the course, each team provided, like in previous years, a written report plus an oral presentation of the realized project in front of an evaluating jury.

By comparison with students' outcome of previous years, results of these experiments showed significant improvements in both qualitative and quantitative aspects related to this practical part of the course. In terms of quality we noted a remarkable amelioration in the degree of involvement and effective participation of all students, as well as in the written descriptions and in the oral presentations of their respective projects. In terms of quantity, the observed ameliorations concerned the percentage of projects that succeeded in completely reaching their objectives $(78.95 \%$ compared to less than $60 \%$ in previous years); the level of accomplishment of the remaining projects (more than $80 \%$ compared to less than $60 \%$ in previous years); and the average grading of this particular part of the course $(84 \%$ compared to $70 \%$ in previous years).

\section{CONCLUSION}

In this paper, we have presented, analyzed and discussed the experimental results of a study case concerning the introduction of new online technologies in order to 
support collaborative and cooperative learning strategies in higher education in Morocco. This study was conducted using the online version of a typical full-semester course of master degree, in which two separated groups of students from two different masters were enrolled.

The course, whose pedagogical approach is mainly based on collaborative and cooperative learning strategies, was designed in 2006 and delivered in traditional nononline form until 2009.

In 2010, an online version of this course was designed and hosted as a pilot class on the Moodle platform of the Swiss Coselearn project for promoting e-learning in francophone African countries, including Morocco.

Students involved in the study were all subscribed to the platform and permanent access to the Internet was ensured to them by the Injaz national initiative for promoting access to new technologies for all engineering and science masters' students. On a technical point of view, conditions were then ideal for undertaking this study.

The experimental results, as developed and discussed in the previous section, showed clearly that the introduction of new online technologies through a specialized elearning platform has resulted in significant improvements of the overall performance of students, by comparison with other students who previously took the same course, using the same pedagogical approach, but in traditional non-line forms.

We showed also that the observed improvements, which have concerned many educational aspects, are the results of an efficient combination between the principles of collaborative and cooperative learning strategies and new e-learning tools that support these principles and facilitate their concrete implementation and application.

These encouraging results suggest a paradigm change in the way we teach and learn. In a world of digital communications, teaching and learning are indeed no longer about content transfer but rather about knowledge construction and skills development; which implies dramatic changes in the roles of both educators and learners.

Teaching should take place in authentic environments where educators are no longer the only source of skills and knowledge, and where learning consists in engagement, experimentation, and communication.

In higher education, such environments can be easily created using e-learning technologies. And in Morocco, this is currently possible at least for engineering and science masters' courses for which permanent access to the Internet is guaranteed for all students.

The generalization of this possibility to lower degrees, where the number of students is generally more important, would finally bring a mitigation to the problem of massification, which is currently one of the most challenging problems facing higher education in Morocco.

But for this to happen, there is a big need for increasing awareness of administrative managers about the benefits of new learning strategies and new technologies that support them, as well as for training the teaching profession, particularly teachers who have many years of experience in using only the traditional "talk and chalk" method.

\section{ACKNOWLEDGMENT}

The authors warmly thank the Coselearn project managers for providing the opportunity of hosting the online version of the course used in this case study as a pilot class on their project's Moodle platform.

\section{REFERENCES}

[1] D. W. Johnson, G. Maruyama, R. T. Johnson, D. Nelson, L. Skon, "Effects of cooperative, competitive, and individualistic goal structures on achievement: a meta-analysis," Psychological Bulletin, vol. 89(1), pp. 47-62, Jan 1981. http://dx.doi.org/ 10.1037/0033-2909.89.1.47

[2] D. W. Johnson, R. T. Johnson, "Student-student interaction: ignored but powerful," Journal of Teacher Education, vol. 36(4), pp. 22-26, July 1985. http://dx.doi.org/10.1177/002248718 503600406

[3] K. A. Smith, "The craft of teaching cooperative learning: an active learning strategy," In: Proceeding Frontiers in Education Conference, pp. 188-193, 1989. http://dx.doi.org/10.1109/ FIE.1989.69400

[4] 1D. Laurillard, "Effective use of technology in teaching and learning in higher education," International Encyclopedia of Education, $3^{\text {rd }}$ ed., pp. 419-426, 2010.

[5] M. V. López-Pérez, M. C. Pérez-López, L. Rodríguez-Ariza, "Blended learning in higher education: students' perceptions and their relation to outcomes," Computers \& Education, vol. 56(3), pp. 818-826, April 2011. http://dx.doi.org/10.1016/ j.compedu.2010.10.023

[6] M. Prince, "Does Active Learning Work? A Review of the Research,” J. Engr. Education, vol. 93(3), pp. 233-231, 2004.

[7] S. G. McNeil, B. R. Robin, R. M. Miller, "Facilitating interaction, communication and collaboration in online courses," Computers \& Geosciences, vol. 26 (6), pp. 699-708, 2000. http://dx.doi.org/10.1016/S0098-3004(99)00106-5

[8] http://www.injaz.ma/ last access 06 July 2013.

[9] http://moodle.org/ last access 06 July 2013.

[10] http://projets.coselearn.org/ last access 06 July 2013.

[11] http://docs.moodle.org/22/en/Philosophy last access 06 July 2013.

\section{AUTHORS}

Abdelaziz Bouroumi is Professor of computer science and information processing at Ben M'sik Faculty of Sciences, Hassan II Mohammedia-Casablanca University, Av Cdt El Harti P.O 7955 Sidi Othmane Casablanca, Morocco (e-mail: a.bouroumi@gmail.com). His current research interests include unsupervised learning, deep learning, collaborative and cooperative learning, e-learning and (recently) m-learning.

Rkia Fajr is a $\mathrm{PhD}$ student in the Information Processing Laboratory of Ben M'sik Faculty of Sciences, Hassan II Mohammedia-Casablanca University, Av Cdt El Harti P.O 7955 Sidi Othmane Casablanca, Morocco (email: fajr.rkia@gmail.com). Her current research project focuses on collaborative learning and e-learning.

Submitted 29 July 2013. Published as re-submitted by the authors 11 February 2014 